\title{
Zeólita na dieta de bovinos de corte
}

[Zeolite in the diet of beef cattle]

\author{
L.R.A. Câmara ${ }^{1}$, S.C. Valadares Filho ${ }^{2}$, M.I. Leão ${ }^{2}$, R.F.D. Valadares ${ }^{2}$, M. Dias ${ }^{3}$ A.P.C. Gomide ${ }^{1}$, \\ A.C.W. Barros ${ }^{4}$, V.A. Nascimento ${ }^{3}$, D.J. Ferreira ${ }^{1}$, J.T. Faé ${ }^{5}$, C. Carneiro ${ }^{1}$, L.L. Cardoso ${ }^{5}$ \\ ${ }^{1}$ Aluno de pós-graduação - Universidade Federal de Viçosa - Viçosa, MG \\ ${ }^{2}$ Universidade Federal de Viçosa - Viçosa, MG \\ ${ }^{3}$ Universidade Federal de Goiás - Campus, Jataí, GO \\ ${ }^{4}$ Aluno de graduação - Univiçosa - Viçosa, MG \\ ${ }^{5}$ Aluno de graduação - Universidade Federal de Viçosa - Viçosa, MG
}

\begin{abstract}
RESUMO
Avaliou-se o efeito da inclusão de zeólita na dieta de bovinos de corte sobre os parâmetros ruminais, as digestibilidades total e parcial, a produção de nitrogênio, a eficiência microbiana e as características do sangue. Os tratamentos, com base na matéria seca (MS) da dieta, foram: 0;0,75;1,5;2,25 e 3,0\% de zeólita. Utilizaram-se cinco bovinos machos mestiços, fistulados no rúmen e abomaso, alimentados com silagem de milho e concentrado, representando $65 \%$ de volumoso e $35 \%$ de concentrado. $\mathrm{O}$ delineamento utilizado foi em quadrado latino $5 \times 5$, com cinco períodos de 15 dias. Os animais receberam $15 \mathrm{~g}$ de dióxido de titânio $\left(\mathrm{TiO}_{2}\right)$ do terceiro ao $12^{\circ}$ dia de cada período. Houve efeito $(\mathrm{P}<0,05)$ sobre o consumo diário $(\mathrm{kg} /$ dia $)$ de proteína bruta $(\mathrm{PB})$ e efeito $(\mathrm{P}<0,05)$ sobre o consumo de MS e de fibra em detergente neutro corrigida para cinza e proteína, expresso em $\mathrm{g} / \mathrm{kg}$ de peso. A digestibilidade total dos nutrientes digestíveis totais (NDT) foi influenciada pelos tratamentos $(\mathrm{P}<0,05)$. A digestibilidade ruminal dos carboidratos não fibrosos $(\mathrm{CNF})$ foi afetada quadraticamente $(\mathrm{P}<0,05)$, assim como a intestinal da $\mathrm{PB}$ e dos CNF. A ingestão e a excreção fecal de nitrogênio ( $\mathrm{g} / \mathrm{dia})$ foram influenciadas linearmente $(\mathrm{P}<0,05)$ pela inclusão de zeólita. Concluiu-se que a adição de zeólita na dieta, embora tenha aumentado os consumos de MS e de FDN, não melhorou a utilização da ureia em dietas de bovinos de corte.
\end{abstract}

Palavras-chave: bovino de corte, aditivo, clinoptilolita, digestibilidade, nutrição

\begin{abstract}
We evaluated the effect of the inclusion of zeolite in the diet of beef cattle on the ruminal digestibility, total and partial production of nitrogen, microbial efficiency and blood characteristics. Treatments based on the dietary dry matter (DM) were: $0 \%, 0.75 \%, 1.5 \%, 2.25 \%$ and $3.0 \%$ of zeolite. We used five crossbred steers fistulated in the rumen and abomasum, fed corn silage and concentrate, representing $65 \%$ forage and $35 \%$ concentrate. The design was a $5 \times 5$ latin square with five periods of 15 days. The animals received $15 \mathrm{~g}$ of titanium dioxide (TiO2) from the third to the $12^{\text {th }}$ day of each period. A significant effect $(P<0.05)$ on the daily consumption $(\mathrm{kg} /$ day) of crude protein $(C P)$ was observed $(P<0.05)$ for DM intake and neutral detergent fiber corrected for ash and protein (NDFap) expressed in $\mathrm{g} / \mathrm{kg}$. The total digestibility of total digestible nutrients (TDN) was influenced by treatments $(P<0.05)$. Ruminal digestibility of non-fiber carbohydrates $(N F C)$ was affected quadratically $(P<0.05)$ as well as intestinal $C P$ and NFC. Intake and fecal excretion of nitrogen (g/day) were affected linearly $(P<0.05)$ by adding zeolite. It was concluded that the addition of zeolite in the diet, while increasing the intake of DM and NDF, did not improve the use of urea in the diet of beef cattle.
\end{abstract}

Keywords: beef cattle, additive, clinoptilolite, digestibility, nutrition

Recebido em 20 de abril de 2011

Aceito em 31 de janeiro de 2012

E-mail: larys01@yahoo.com.br 


\section{INTRODUÇÃO}

A alimentação é o principal fator de custo da exploração de bovinos de corte; assim, é importante o estudo de alternativas que possam aumentar a capacidade de aproveitamento da dieta pelos animais, tornando-a mais viável. Entre as alternativas, algumas já consolidadas, está a utilização de aditivos, como os antibióticos, ionóforos, tamponantes e outros em avaliação, como a zeólita. Considerando-se o alto custo da proteína da dieta, a economia da produção animal é altamente dependente da eficiência de sua utilização. Por esse motivo, nos últimos anos, houve considerável interesse na redução das perdas de compostos nitrogenados (N) pelos ruminantes (Russel, 1992). Durante muito tempo, procurou-se atingir esses objetivos por meio da manipulação da dieta, porém, nas últimas décadas, um grande número de compostos químicos tem sido testado para os mesmos fins. Os aluminossilicatos são uma classe desses compostos que teve considerável sucesso como aditivo alimentar.

As zeólitas são minerais silicatos hidratados de alumínio, juntamente com metais alcalinos e alcalinos terrosos normalmente encontrados em rochas sedimentares. Castro et al. (1990) observaram que a alta capacidade de troca catiônica e a marcada preferência pelo $\mathrm{NH}_{4}{ }^{+}$, $\mathrm{K}^{+}, \mathrm{Ca}^{2+}, \mathrm{Na}^{+} \mathrm{e} \mathrm{Mg}^{2+}$ fazem crer que a zeólita tem alto potencial para ser usada como aditivo alimentar.

A ureia é um composto nitrogenado não proteico que, quando ingerido, é hidrolisado em amônia. Os íons de amônia formados pela decomposição enzimática da ureia no rúmen são imediatamente trocados nas estruturas cristalinas da zeólita, onde permanecem por várias horas até que sejam liberados pela ação regeneradora do íon sódio provindo da saliva. Desse modo, a liberação gradual do íon amônio no rúmen permite aos microrganismos uma síntese contínua de proteína microbiana (Cass et al., 1994) para melhor absorção no trato gastrintestinal do animal, e o produto resultante da ureia com zeólita pode trazer efeitos positivos na utilização desse suplemento nitrogenado para ruminantes, porém a exata função das zeólitas como aditivo na alimentação animal ainda não está bem definida. Portanto, objetivou-se avaliar o efeito da zeólita no trato digestivo dos bovinos de corte, sua digestibilidade, sua influência nos parâmetros fisiológicos, bem como a dinâmica exercida nos compartimentos rúmen-retículo.

\section{MATERIAL E MÉTODOS}

Foram utilizados cinco tratamentos constituídos da adição, com base na matéria seca (MS) da dieta, de quantidades crescentes, $0 ; 0,75 ; 1,5$; 2,25 e $3,0 \%$, de zeólita - aditivo nutricional comercial à base de clinoptilolita, um aluminossilicato hidratado. As dietas foram constituídas de $65 \%$ de silagem de milho e $35 \%$ de concentrado e balanceadas de acordo com o Nutrients... (2000) para serem isoproteicas. Utilizaram-se cinco animais mestiços da raça Gir, com peso médio inicial de $297,76 \mathrm{~kg}$ ( \pm $29,53 \mathrm{~kg}$ ), fistulados no rúmen e no abomaso, distribuídos em quadrado latino $5 \times 5$, mantidos confinados em baias individuais de alvenaria de $3 \mathrm{~m}^{2}$, cobertas, com bebedouros automáticos e comedouros. O experimento foi constituído por cinco períodos, com duração de 15 dias cada, totalizando 75 dias, sendo os nove primeiros dias de adaptação às dietas e os demais destinados às coletas.

A alimentação foi fornecida duas vezes ao dia, às oito e às $16 \mathrm{~h}$. Diariamente, foram feitas pesagens das quantidades de alimentos fornecidos e das sobras de cada tratamento, para estimar $\mathrm{o}$ consumo e manter para as sobras em torno de $10 \%$, com base na matéria natural. Do primeiro ao nono dia de cada período, foi realizada adaptação dos animais às dietas experimentais. A proporção dos ingredientes utilizados, a composição bromatológica dos concentrados e a composição bromatológica das dietas experimentais estão apresentadas, respectivamente, nas Tab. 1, 2 e 3 .

Durante o período de coletas, do $10^{\circ}$ ao $15^{\circ}$ dia, foram feitas amostragens dos alimentos fornecidos e das sobras para posteriores análises. Para determinação do fluxo de matéria seca fecal, foram efetuadas coletas totais de fezes do $10^{\circ}$ ao $13^{\circ}$ dia de cada período experimental. Nesse mesmo período, também foram feitas coletas totais de urina. As coletas totais de fezes e de urina foram realizadas, iniciando-se imediatamente antes do arraçoamento matinal do primeiro dia de coletas, estendendo-se durante três dias consecutivos. A coleta total de fezes foi obtida pela defecação espontânea de cada animal, e na coleta de urina foram utilizadas bolsas coletoras colocadas na região prepucial. 
Tabela 1. Proporção dos ingredientes utilizados nos concentrados experimentais de bovinos de corte

\begin{tabular}{lccccc}
\hline \multirow{2}{*}{ Item } & \multicolumn{5}{c}{ Zeólita (\%)* } \\
\cline { 2 - 6 } & 0 & 0,75 & 1,5 & 2,25 & 3,0 \\
\hline Fubá de milho & 93,4 & 91,42 & 89,44 & 87,46 & 85,48 \\
Ureia/SA & 4,6 & 4,68 & 4,76 & 4,84 & 4,92 \\
Zeólita $_{\text {Sal mineral }^{1}}$ & 0,0 & 1,9 & 3,0 & 5,7 & 7,6 \\
\hline
\end{tabular}

* Porcentagem na MS.

${ }^{1}$ Composição sal mineral: $50 \%$ fosfato bicálcico, $47,74 \%$ sal comum, $1,4 \%$ sulfato de zinco, $0,7 \%$ sulfato de cobre, $0,05 \%$ sulfato de cobalto, $0,05 \%$ iodato de potássio, $0,01 \%$ selenito de sódio, $0,05 \%$ sulfato de magnésio.

Tabela 2. Composição bromatológica dos concentrados experimentais com adição de zeólita (base na matéria seca) usados para bovinos de corte

\begin{tabular}{lccccc}
\hline \multirow{2}{*}{ Item } & 0 & 0,75 & 1,5 & 2,25 & 3 \\
\cline { 2 - 6 } & 88,41 & 88,63 & 88,04 & 89,01 & 89,19 \\
MS & 91,63 & 89,68 & 87,74 & 85,80 & 83,86 \\
MO & 20,07 & 20,09 & 20,12 & 20,14 & 20,16 \\
PB & 11,59 & 11,79 & 12,00 & 12,20 & 12,40 \\
PBU & 3,88 & 3,79 & 3,17 & 3,63 & 3,55 \\
EE & 12,94 & 12,66 & 12,39 & 12,11 & 11,84 \\
FDNcp & 61,73 & 60,25 & 58,76 & 57,28 & 55,79 \\
CNF & 1,08 & 1,06 & 1,03 & 1,01 & 0,99 \\
Lignina & &
\end{tabular}

$\mathrm{MS}=$ matéria seca; $\mathrm{MO}=$ matéria orgânica; $\mathrm{PB}=$ proteína bruta; $\mathrm{PBU}=$ proteína bruta da ureia; $\mathrm{EE}=$ extrato etéreo; $\mathrm{FDNcp}=$ fibra em detergente neutro corrigida para cinzas e proteínas; $\mathrm{CNF}=$ carboidratos não fibrosos.

Tabela 3. Composição bromatológica das dietas experimentais (concentrado + volumoso) com adição de zeólita usadas para bovinos de corte

\begin{tabular}{lccccc}
\hline \multirow{2}{*}{ Item } & \multicolumn{5}{c}{ Zeólita $(\%$ da MS) } \\
\cline { 2 - 5 } & 0 & 0,75 & 1,5 & 2,25 & 3,00 \\
\hline MS & 88,86 & 88,93 & 88,72 & 89,06 & 89,13 \\
MO & 95,84 & 95,15 & 94,47 & 93,80 & 93,12 \\
PB & 11,75 & 11,76 & 11,77 & 11,77 & 11,78 \\
EE & 4,06 & 4,02 & 4,00 & 3,97 & 3,94 \\
FDNcp & 38,46 & 38,36 & 38,27 & 38,17 & 38,07 \\
CNF & 41,28 & 40,76 & 40,24 & 39,72 & 39,20 \\
Lignina & 3,61 & 3,60 & 3,59 & 3,58 & 3,57 \\
\hline
\end{tabular}

$\mathrm{MS}=$ matéria seca; $\mathrm{MO}=$ matéria orgânica; $\mathrm{PB}=$ proteína bruta; $\mathrm{EE}=$ extrato etéreo; $\mathrm{CNF}=$ carboidratos não fibrosos; $\mathrm{FDNcp}=$ fibra em detergente neutro corrigida para cinzas e proteínas.

O fluxo de matéria seca abomasal foi estimado utilizando-se o indicador dióxido de titânio $\left(\mathrm{TiO}_{2}\right)$, fornecido do terceiro ao $12^{\circ}$ dia de cada período experimental, via fístula ruminal, na dose diária de $15 \mathrm{~g}$, acondicionado em cartuchos de papel, quatro horas após o arraçoamento matinal (12h). As coletas de digesta de abomaso foram efetuadas do $10^{\circ}$ ao $13^{\circ}$ dia, em quantidades de aproximadamente $200 \mathrm{~mL}$, duas vezes ao dia, em intervalos de $15 \mathrm{~h}$ (Allen e Linton, 2007). O fluxo de matéria seca abomasal foi calculado dividindo-se o consumo de $\mathrm{TiO}_{2}$ pela sua concentração na MS abomasal.
O isolamento bacteriano foi realizado conforme técnica descrita por Cecava et al. (1990), sendo obtidas amostras seis horas após a alimentação matinal no $13^{\circ}$ dia e antes da primeira alimentação, no $14^{\circ}$ dia. Neste último dia, foi coletada amostra de sangue, via veia jugular, quatro horas após o arraçoamento matinal, em tubos contendo gel acelerador de coagulação e estabilizantes, sendo as amostras imediatamente centrifugadas (1.500rpm por 15 minutos) e o soro congelado para posteriores análises de glicose e ureia. 
Foram realizadas coletas de líquido ruminal, via fístula ruminal, no $15^{\circ}$ dia de cada período, para avaliação do $\mathrm{pH}$ e da concentração de nitrogênio amoniacal no rúmen. Foram coletados $50 \mathrm{~mL}$ de líquido ruminal nos tempos zero (antes da alimentação) e um, dois, três, quatro, seis, oito, nove, $10,11,12,20$ e 24 horas após o fornecimento da alimentação. As amostras foram filtradas por uma camada tripla de gases e submetidas à avaliação do $\mathrm{pH}$ por intermédio do peagâmetro digital. Previamente filtradas (40mL), elas foram acondicionadas em recipiente contendo $1 \mathrm{~mL}$ de ácido sulfúrico $\left(\mathrm{H}_{2} \mathrm{SO}_{4}\right)$ 1:1, e armazenadas a $-15^{\circ} \mathrm{C}$ para análises posteriores de nitrogênio amoniacal $\left(\mathrm{N}-\mathrm{NH}_{3}\right)$ segundo Chaney e Marbach (1962). As amostras de fezes e de digesta do abomaso foram devidamente identificadas e secas em estufa com circulação forçada de ar a $60^{\circ} \mathrm{C}$, por $72 \mathrm{~h}$ (Silva e Queiroz, 2002). Nas análises químico-bromatológicas, foram avaliados os teores de matéria seca (MS), matéria mineral (MM), compostos nitrogenados totais e extrato etéreo (EE), de acordo com técnicas descritas por Silva e Queiroz (2002), enquanto as determinações de fibra em detergente neutro (FDN) e fibra em detergente ácido (FDA) foram realizadas de acordo com o método proposto por Van Soest e Robertson (1985). No resíduo de FDN, foi realizada a análise de proteína e cinzas para obtenção da FDN corrigida para cinzas e proteína (FDNcp). Os carboidratos não fibrosos (CNF) dos alimentos foram obtidos pela equação proposta por Hall (2000):

$\mathrm{CNF}=100-[(\% \mathrm{~PB}-\% \mathrm{~PB}$ da ureia $+\%$ ureia $)$ $+\% \mathrm{FDNcp}+\% \mathrm{EE}+\%$ cinzas $]$.

O teor de dióxido de titânio foi determinado segundo Myers et al. (2004).

Para recuperação dos indicadores internos, foram feitas análises de fibra em detergente neutro indigestível (FDNi) e fibra em detergente ácido indigestível (FDAi), em que as amostras foram incubadas por 264 horas no rúmen de uma vaca (Casali et al., 2008). A estimativa dos nutrientes digestíveis totais (NDT) foi obtida para cada animal, dentro de seu tratamento e período, pela equação:

$\mathrm{NDT}=\mathrm{PBD}+($ EED $\times 2,25)+\mathrm{FDND}+\mathrm{CNFD}$, em que: $\mathrm{PBD}=$ proteína bruta digestível; $\mathrm{EED}=$ extrato etéreo digestível; FDND = fibra em detergente neutro digestível; CNFD = carboidratos não fibrosos digestíveis.

Nas amostras de urina, foram determinadas as concentrações de alantoína , ácido úrico, ureia e creatinina. A determinação de alantoína foi descrita por Young e Conway (1942), citados por Chen e Gomes (1992). As concentrações de ácido úrico, ureia e creatinina foram estimadas na urina utilizando-se kits comerciais (Labtest), seguindo orientações descritas pelo fabricante.

As purinas microbianas absorvidas (X, mmoL/dia) foram calculadas a partir da excreção de derivados de purinas (Y, mmol/dia), por intermédio da equação $\mathrm{Y}=0,85 \mathrm{X}+0,385$ $\mathrm{PV}^{0,75}$ (Verbic et al., 1990). O fluxo intestinal de compostos nitrogenados (N) microbianos (Y, gN/dia) foi calculado em função das purinas microbianas absorvidas (X, mmol/dia), utilizando-se a equação $\mathrm{Y}=$ $(70 \mathrm{X}) /(0,83 \times 0,116 \times 1000)$ (Chen e Gomes, 1992). A quantificação da biomassa microbiana nas amostras do rúmen e abomaso foram feitas utilizando-se as bases purinas como indicadores (Ushida et al., 1985).

Todas as análises foram realizadas utilizando-se o programa Statistical... (2002) a 5\% de probabilidade. $\mathrm{O}$ consumo de nutrientes, as digestibilidades total (considerando a coleta total de fezes) e parcial foram realizados por mínimos quadrados. A comparação entre as diferentes quantidades de zeólita quanto ao balanço de nitrogênio, excreção de derivados de purinas urinárias, purinas absorvidas e produção e eficiência microbiana foi realizada por contrastes ortogonais com posterior ajuste de regressão.

\section{RESULTADOS E DISCUSSÃO}

A adição de diferentes quantidades de zeólita na dieta não influenciou $(\mathrm{P}>0,05)$ o consumo diário dos nutrientes (kg/dia) avaliados quando os demais níveis de adição de zeólita foram comparados ao nível $0 \%$ (controle), exceto da $\mathrm{PB}$, que aumentou linearmente $(\mathrm{P}<0,05)$ com os níveis de zeólita (Tab. 4). Estes resultados assemelham-se aos obtidos por McCollum e Galyean (1983), que não encontraram efeito da zeólita no consumo de MS e MO, o que, consequentemente, não afetou o consumo dos demais nutrientes, exceto a proteína bruta. 
Tabela 4. Médias ajustadas para os consumos diários de matéria seca e nutrientes, emkg/dia e g/kg PV

\begin{tabular}{|c|c|c|c|c|c|c|c|c|c|c|c|c|}
\hline \multirow{3}{*}{ Variável } & \multicolumn{5}{|c|}{ Zeólita (\%) } & \multirow{2}{*}{ Média } & \multirow{2}{*}{$\begin{array}{l}\mathrm{CV} \\
(\%)\end{array}$} & \multirow{2}{*}{$\begin{array}{l}\text { Valor } \\
\text { de P }\end{array}$} & \multicolumn{4}{|c|}{ Efeito $^{1,2}$} \\
\hline & 0,0 & 0,75 & 1,50 & 2,25 & 3,00 & & & & $\mathrm{~L}$ & $\mathrm{Q}$ & $\mathrm{C}$ & QT \\
\hline & \multicolumn{5}{|c|}{$\mathrm{kg} / \mathrm{dia}$} & & & & & & & \\
\hline MS & 6,23 & 6,40 & 6,49 & 6,46 & 6,74 & 6,46 & 7,01 & 0,53 & 0,117 & 0,915 & 0,560 & 0,792 \\
\hline MO & 5,76 & 5,89 & 5,95 & 5,89 & 6,12 & 5,92 & 6,98 & 0,74 & 0,244 & 0,918 & 0,560 & 0,783 \\
\hline PB & 0,62 & 0,63 & 0,65 & 0,65 & 0,67 & 0,64 & 6,63 & 0,31 & 0,046 & 0,943 & 0,817 & 0,590 \\
\hline $\mathrm{EE}$ & 0,23 & 0,23 & 0,23 & 0,23 & 0,24 & 0,23 & 7,21 & 0,98 & 0,632 & 0,762 & 0,503 & 0,975 \\
\hline FDNcp & 2,67 & 2,75 & 2,79 & 2,76 & 2,88 & 2,77 & 0,39 & 0,62 & 0,163 & 0,975 & 0,545 & 0,732 \\
\hline $\mathrm{CNF}$ & 2,34 & 2,38 & 2,38 & 2,36 & 2,44 & 2,38 & 0,66 & 0,89 & 0,449 & 0,843 & 0,537 & 0,900 \\
\hline \multirow[t]{2}{*}{ NDT } & 4,53 & 4,63 & 4,65 & 4,51 & 4,71 & 4,60 & 7,25 & 0,85 & 0,609 & 0,939 & 0,378 & 0,656 \\
\hline & \multicolumn{5}{|c|}{$\mathrm{g} / \mathrm{kg} \mathrm{PV}$} & & & & & & & \\
\hline MS & 19,53 & 19,40 & 20,22 & 20,28 & 20,88 & 20,06 & 4,47 & 0,12 & 0,015 & 0,639 & 0,772 & 0,384 \\
\hline MO & 18,07 & 17,86 & 18,53 & 18,48 & 18,96 & 18,38 & 4,49 & 0,30 & 0,061 & 0,641 & 0,768 & 0,379 \\
\hline FDNcp & 8,38 & 8,32 & 8,70 & 8,66 & 8,92 & 8,60 & 5,07 & 0,23 & 0,039 & 0,777 & 0,818 & 0,349 \\
\hline
\end{tabular}

MS = matéria seca; $\mathrm{MO}=$ matéria orgânica; $\mathrm{PB}=$ proteína bruta; $\mathrm{EE}=$ extrato etéreo; FDNcp = fibra em detergente neutro corrigida para cinzas e proteínas; $\mathrm{CNF}=$ carboidratos não fibrosos; $\mathrm{NDT}=$ nutrientes digestíveis totais .

${ }^{1}$ Probabilidade para o erro tipo I associado à hipótese de nulidade relacionada à ausência de efeito.

${ }^{2} \mathrm{~PB}(\mathrm{~kg} / \mathrm{dia})=0,6176+0,0176$ trat $\left(\mathrm{r}^{2}=0,9738\right) ; \mathrm{MS}(\mathrm{g} / \mathrm{kg} \mathrm{PV})=19,3486+0,4765$ trat $\left(\mathrm{r}^{2}=0,9619\right) ;$ FDNcp $(\mathrm{g} / \mathrm{kg}$ $\mathrm{PV})=8,3112+0,1904\left(\mathrm{r}^{2}=0,9593\right)$.

Apesar de a dieta total ter sido formulada para que fosse isoproteica, a pequena variação na sua composição aliada à pequena variação no CMS foi suficiente para apresentar efeito linear $(\mathrm{P}<0,05)$ no consumo de $\mathrm{PB}$.

Com relação ao consumo dos nutrientes, expresso em $\mathrm{g} / \mathrm{kg} \mathrm{PV}$, não houve diferença $(\mathrm{P}>0,05)$ nos consumos de $\mathrm{MO}$ entre os níveis de zeólita da dieta, porém houve aumento linear $(\mathrm{P}<0,05)$ no consumo de MS e FDNcp (Tab. 4). Resultados semelhantes foram observados por Mumpton e Fishman (1977) e Sweeney et al. (1983), mas, quando esses autores avaliaram a resposta de crescimento e ganho de peso dos animais, o resultado não foi consistente, segundo esses autores. Entretanto, Coutinho Filho (2002) encontrou resultados diferentes dos descritos neste experimento, em que, ao adicionar zeólita, os animais não apresentaram aumento no consumo de MS e FDNcp.

De acordo com Russel e Chow (1993), aditivos ricos em minerais seriam capazes de aumentar a osmolaridade, aumentando o consumo de água e salivação e, consequentemente, aumentar a taxa de passagem. O acréscimo de zeólita incrementou a matéria mineral presente na dieta, o que deve ter resultado em maior consumo de água pelo animal, a fim de respeitar a lei da isosmolaridade. Dessa forma, pode ocorrer um aumento na taxa de passagem, o que explicaria o maior consumo de matéria seca. Entretanto, de acordo com Fatehi et al. (2008), o aumento na ingestão de MS teria outras razões. Uma delas seria a diluição da dieta com o acréscimo de zeólita, levando o animal a ingerir uma quantidade maior de MS para abastecer suas necessidades. Outra razão seria o aumento da digestibilidade do alimento, o qual acarretaria um maior consumo de MS, e sua terceira explicação para o aumento no consumo de MS estaria relacionada com o balanço cátionânionico da dieta, o que levaria ao maior consumo pelo animal a fim de manter o equilíbrio ácido-base do sangue.

Não houve efeito da inclusão de zeólita $(\mathrm{P}>0,05)$ sobre a digestibilidade total dos nutrientes. Isso pode ser atribuído à ausência de efeito de zeólita sobre o consumo de nutrientes. O teor de NDT das dietas reduziu-se linearmente $(\mathrm{P}<0,05)$ em função dos níveis de zeólita, provavelmente devido à substituição do milho pela zeólita, diminuindo a porcentagem de nutrientes digestíveis totais da dieta. Resultados semelhantes foram encontrados por Parré et al. (1997) e Galindo et al. (1990), nos quais os autores não encontraram efeito da zeólita na digestibilidade. As digestibilidades ruminais dos nutrientes, excetuando-se CNF (Tab. 5), não foram afetadas $(\mathrm{P}>0,05)$, demonstrando que a adição crescente de zeólita não interferiu na digestibilidade ruminal desses nutrientes; resultados semelhantes aos encontrados por McCollum e Galyean (1983), que também não encontraram valores significativos para digestibilidade ruminal dos nutrientes. A 
digestibilidade ruminal dos CNF foi afetada de forma quadrática $(\mathrm{P}<0,05)$ pela quantidade de zeólita, estimando-se valor mínimo de $75,0 \%$ com a adição de 1,55\% de zeólita à dieta.
A adição de zeólita não influenciou (P>0,05) a digestibilidade intestinal de $\mathrm{MS}, \mathrm{MO}, \mathrm{EE}$ e FDNcp, porém afetou $(\mathrm{P}<0,05)$ a digestibilidade intestinal da PB e dos CNF (Tab. 6).

Tabela 5. Coeficiente de digestibilidade ruminal, em função da quantidade de zeólita

\begin{tabular}{|c|c|c|c|c|c|c|c|c|c|c|c|c|}
\hline \multirow{2}{*}{ Variável } & \multicolumn{5}{|c|}{ Zeólita (\%) } & \multirow{2}{*}{ Média } & \multirow{2}{*}{$\begin{array}{l}\mathrm{CV} \\
(\%)\end{array}$} & \multirow{2}{*}{$\begin{array}{l}\text { Valor } \\
\text { de P }\end{array}$} & \multicolumn{4}{|c|}{ Efeito $^{1,2}$} \\
\hline & 0,0 & 0,75 & 1,50 & 2,25 & 3,00 & & & & L & Q & $\mathrm{C}$ & QT \\
\hline $\mathrm{MS}^{3}$ & 65,54 & 66,49 & 66,20 & 73,81 & 71,21 & 68,65 & 11,72 & 0,43 & 0,127 & 0,953 & 0,445 & 0,384 \\
\hline $\mathrm{MO}^{3}$ & 72,25 & 72,69 & 72,94 & 79,34 & 77,69 & 74,98 & 9,64 & 0,43 & 0,111 & 0,873 & 0,456 & 0,563 \\
\hline $\mathrm{PB}^{4}$ & 7,75 & 10,43 & 3,87 & 0,43 & $-0,66$ & 4,36 & 12,66 & 0,57 & 0,143 & 0,831 & 0,511 & 0,776 \\
\hline $\mathrm{EE}^{4}$ & 16,40 & 14,66 & 11,34 & 29,72 & 19,93 & 18,41 & 13,16 & 0,14 & 0,170 & 0,760 & 0,105 & 0,093 \\
\hline $\mathrm{FDNcp}^{3}$ & 88,69 & 96,02 & 91,24 & 107,11 & 93,24 & 95,26 & 17,94 & 0,51 & 0,420 & 0,462 & 0,480 & 0,218 \\
\hline $\mathrm{CNF}^{3}$ & 83,51 & 77,53 & 76,78 & 75,64 & 85,60 & 79,81 & 7,44 & 0,13 & 0,805 & 0,018 & 0,506 & 0,497 \\
\hline
\end{tabular}

MS = matéria seca; $\mathrm{MO}=$ matéria orgânica; $\mathrm{PB}$ = proteína bruta; $\mathrm{EE}$ = extrato etéreo; FDNcp = fibra em detergente neutro corrigida para cinzas e proteínas; $\mathrm{CNF}=$ carboidrato não fibroso.

${ }^{1}$ Probabilidade para o erro tipo I associado à hipótese de nulidade relacionada à ausência de efeito.

${ }^{2} \mathrm{CNF}(\%)=0,8140-0,1217$ trat $+0,0396 \operatorname{trat}^{2}\left(\mathrm{r}^{2}=0,7722\right)$.

${ }^{3} \%$ do total digestível.

${ }^{4} \%$ de ingerido.

Tabela 6. Coeficientes de digestibilidade intestinal, em função da quantidade de zeólita

\begin{tabular}{|c|c|c|c|c|c|c|c|c|c|c|c|c|}
\hline \multirow{2}{*}{ Variável } & \multicolumn{5}{|c|}{ Zeólita (\%) } & \multirow{2}{*}{ Média } & \multirow{2}{*}{$\begin{array}{l}\mathrm{CV} \\
(\%)\end{array}$} & \multirow{2}{*}{$\begin{array}{l}\text { Valor } \\
\text { de P }\end{array}$} & \multicolumn{4}{|c|}{ Efeito $^{1,2}$} \\
\hline & 0,0 & 0,75 & 1,50 & 2,25 & 3,00 & & & & $\mathrm{~L}$ & Q & $\mathrm{C}$ & QT \\
\hline $\mathrm{MS}^{3}$ & 34,46 & 33,51 & 33,80 & 26,19 & 28,79 & 31,35 & 25,67 & 0,43 & 0,127 & 0,953 & 0,445 & 0,384 \\
\hline $\mathrm{MO}^{3}$ & 27,75 & 27,31 & 27,05 & 20,65 & 22,30 & 25,01 & 28,89 & 0,43 & 0,111 & 0,873 & 0,456 & 0,563 \\
\hline $\mathrm{PB}^{4}$ & 62,66 & 63,18 & 56,26 & 54,97 & 56,30 & 58,67 & 8,36 & 0,05 & 0,010 & 0,396 & 0,173 & 0,399 \\
\hline $\mathrm{EE}^{4}$ & 83,24 & 80,43 & 81,36 & 77,65 & 79,97 & 80,53 & 9,28 & 0,82 & 0,394 & 0,660 & 0,832 & 0,507 \\
\hline $\mathrm{FDNcp}^{3}$ & 11,31 & 3,98 & 8,76 & $-7,11$ & 6,76 & 4,74 & 360,67 & 0,51 & 0,420 & 0,462 & 0,480 & 0,218 \\
\hline $\mathrm{CNF}^{2,3}$ & 16,48 & 22,47 & 23,21 & 24,35 & 14,40 & 20,18 & 28,22 & 0,13 & 0,805 & 0,018 & 0,506 & 0,497 \\
\hline
\end{tabular}

$\mathrm{MS}=$ matéria seca; $\mathrm{MO}=$ matéria orgânica; $\mathrm{PB}=$ proteína bruta; $\mathrm{EE}=$ extrato etéreo; FDNcp= fibra em detergente neutro corrigida para cinzas e proteínas.

${ }^{1}$ Probabilidade para o erro tipo I associado à hipótese de nulidade relacionada à ausência de efeito.

${ }^{2} \mathrm{~PB}(\%)=62,8639-2,7936 \operatorname{trat}^{2}\left(\mathrm{r}^{2}=0,7067\right) ; \mathrm{CNF}(\%)=16,2759+11,1859$ trat $-3,6065$ trat $^{2}\left(\mathrm{r}^{2}=0,7709\right)$

${ }^{3} \%$ do total digestível.

${ }^{4} \%$ do total que chega ao local.

Esses valores significativos para $\mathrm{PB}$ e $\mathrm{CNF}$ foram diferentes dos encontrados por McCollum e Galyean (1983), que não encontraram diferença estatística na digestibilidade intestinal desses nutrientes. A adição de zeólita interferiu de forma linear e negativa $(\mathrm{P}<0,05)$ na digestibilidade intestinal da PB. A adição de zeólita provocou um efeito quadrático $(\mathrm{P}<0,05)$ na digestão intestinal do CNF (Tab 6). A maior digestibilidade $(24,9 \%)$ foi estimada com $1,55 \%$ de zeólita adicionada à dieta.

Avaliando-se a excreção e o balanço de nitrogênio, somente o ingerido e a excreção fecal de nitrogênio ( $\mathrm{g} / \mathrm{dia}$ ) foram influenciados $(\mathrm{P}<0,05)$ pelos níveis de zeólita na dieta, o que difere dos resultados observados por Parré et al. (1997), que, ao testarem a inclusão da zeólita em rações peletizadas com ureia e farelo de algodão 
para ovinos, verificaram que o uso da zeólita na proporção de $3 \%$ da ração melhorou o balanço de compostos nitrogenados $(\mathrm{N})$. No presente estudo, a adição de zeólita resultou em maior excreção de compostos nitrogenados, porém essa não afetou o balanço de nitrogênio; resultado diferente do encontrado por Sweeney et al. (1983), que trabalharam com zeólita na alimentação animal, já que a principal propriedade da zeólita é a capacidade de reter amônia e liberá-la gradativamente, reduzindo as perdas nitrogenadas nas fezes e urina. Apesar da significância do nitrogênio ingerido e fecal, esses valores não foram capazes de afetar $(\mathrm{P}>0,05)$ o balanço de nitrogênio em nenhum dos tratamentos. Não houve efeito $(\mathrm{P}>0,05)$ dos níveis de zeólita sobre a excreção dos derivados de purina e purinas absorvidas (Tab. 7).

Tabela 7. Excreção de derivados de purinas urinárias e purinas absorvidas, em função da quantidade de zeólita

\begin{tabular}{|c|c|c|c|c|}
\hline \multirow{2}{*}{ Zeólita (\%) } & \multicolumn{3}{|c|}{ Excreção de derivados de purina (mmol/dia) } & \multirow{2}{*}{$\begin{array}{c}\text { Purinas } \\
\text { absorvidas } \\
\text { (mmol/dia) }\end{array}$} \\
\hline & Alantoína & Ácido úrico & Purinas totais & \\
\hline 0,00 & 141,00 & 3,38 & 144,38 & 135,86 \\
\hline 0,75 & 121,49 & 2,47 & 123,93 & 111,95 \\
\hline 1,50 & 134,03 & 3,56 & 137,59 & 128,01 \\
\hline 2,25 & 128,62 & 1,37 & 129,99 & 119,33 \\
\hline 3,00 & 124,05 & 2,10 & 126,15 & 114,03 \\
\hline Média & 129,84 & 2,57 & 132,41 & 121,84 \\
\hline $\mathrm{CV}(\%)$ & 17,75 & 55,31 & 17,84 & 22,52 \\
\hline \multicolumn{5}{|c|}{ Efeito $^{1}$} \\
\hline Linear & 0,4273 & 0,0964 & 0,3806 & 0,3680 \\
\hline Quadrático & 0,7626 & 0,9915 & 0,7676 & 0,7903 \\
\hline Cúbico & 0,3570 & 0,6696 & 0,3815 & 0,3642 \\
\hline Quártico & 0,4405 & $0,0498^{2}$ & 0,3809 & 0,3834 \\
\hline
\end{tabular}

${ }^{1}$ Probabilidade para o erro tipo I associado à hipótese de nulidade relacionada à ausência de efeito.

${ }^{2}$ Ácido úrico $(\mathrm{mmol} /$ dia $)=3,3800-8,8689$ trat $+16,0554$ trat $^{2}-9,0011$ trat $^{3}+1,5292 \operatorname{trat}^{4}\left(\mathrm{r}^{2}=0,8532\right)$.

A proporção média de alantoína, em relação às purinas totais, foi de $98,07 \%$, valor este maior que o observado por Rennó et al. (2000), de $91,9 \%$, em bovinos de corte.

A excreção urinária de ácido úrico foi influenciada $(\mathrm{P}<0,05)$ pela inclusão de zeólita, representando $2,0 \%$ das excreções totais dos derivados de purina na urina, valores bem abaixo dos apontados por Silva et al. (2001), de 10,83. Segundo Johnson et al. (1998), a relação entre ácido úrico e derivados de purina na urina pode variar em função da dieta e do estado fisiológico do animal.

A produção de proteína microbiana e a eficiência de síntese microbiana não foram influenciadas ( $\mathrm{P}>0,05)$ pelos níveis de zeólita. O valor médio encontrado para eficiência de síntese microbiana foi de $122,46 \mathrm{~g} \mathrm{~PB} \mathrm{mic} / \mathrm{kg}$ NDT, semelhante àquele recomendado por Detmann et al. (2010), de $120 \mathrm{~g}$ PB mic/kg NDT. Pode-se inferir, a partir desses resultados, que não houve limitação para o crescimento microbiano.

As concentrações de glicose e ureia plasmática não diferiram $(\mathrm{P}>0,05)$ em função das quantidades de zeólita e mantiveram-se dentro da faixa de normalidade (Manual... 1997). Não houve interação $(\mathrm{P}>0,05)$ de porcentagem de inclusão de zeólita versus tempo de avaliação para o pH e $\mathrm{N}-\mathrm{NH}_{3}$ ruminais. Porém, observou-se efeito $(\mathrm{P}<0,05)$ de tempo de avaliação para essas variáveis; resultado semelhante foi encontrado por Sadeghi e Shawrang (2006). Não houve diferença entre tratamentos quanto ao $\mathrm{pH}$ do líquido ruminal nos diferentes tempos de amostragem, mostrando que a diferença ocorreu apenas em função do tempo, independentemente das dietas experimentais. No presente estudo, os valores de $\mathrm{pH}$ que variaram de 5,66 a 6,93, encontram-se dentro da faixa para o máximo crescimento microbiano citada por Hoover e Stokes (1991), de 5,5 a 7,1. Também não houve efeito $(\mathrm{P}>0,05)$ da dieta sobre a 
concentração ruminal de $\mathrm{N}-\mathrm{NH}_{3}$, assim como não houve efeito $(\mathrm{P}>0,05)$ da quantidade de zeólita sobre a composição das bactérias ruminais.

\section{CONCLUSÕES}

A adição de zeólita na ração na quantidade avaliada não melhora a utilização da ureia em dietas de bovinos de corte, uma vez que não altera o consumo e a digestibilidade de quase todos os nutrientes, bem como não afeta os parâmetros ruminais avaliados.

\section{REFERÊNCIAS}

ALLEN, M.S.; LINTON, J.A. V. In vivo methods to measure digestibility and digestion kinetics of feed fractions in the rumen. In. RENNÓ, F.P.; SILVA, L.F.P. (Eds.) SIMPÓSIO INTERNACIONAL AVANÇOS EM TÉCNICAS DE PESQUISA EM NUTRIÇÃO DE RUMINANTES, Pirassununga, 2007. Anais..., Pirassununga:USP, 2007. p. 72-89.

CASALI, A.O.; DETMANN, E.; VALADARES FILHO, S.C. et al. Influência do tempo de incubação e do tamanho de partículas sobre os teores de compostos indigestíveis em alimentos e fezes bovinas obtidos por procedimentos in situ. Rev. Bras. Zootec., v.37, p.335$342,2008$.

CASS, J.L.; RICHARDSON, C.R.; SMITH, K.J. Evaluation of slow ammonia release from urea/calcium compounds. J. Anim. Sci., v.72, p.243, 1994.

CASTRO, M.E.; LON-WO, R.; GARCÍA-LOPEZ, J. et al. Las zeolitas naturales cubanas en la produccion animal. SEMINÁRIO CIENTÍFICO INTERNACIONAL, XXV Aniversário, Instituto de Ciência Animal, Habana, Cuba, 1990.

CECAVA, M.J.; MERCHEN, N.R.; GAY, L.C. et al. Composition of ruminal bacteria harvested from steers as influenced by dietary energy level, feeding frequency, and isolation techniques. J. Dairy Sci., v.73, p.2480-2888, 1990.

CHANEY, A.L.; MARBACH, E.P. Modified reagents for determination of urea and ammonia. Clin. Chemist., v.8, p.130-132. 1962.

CHEN, X.; GOMES, M.J. Estimation of microbial protein supply to sheep and cattle based on urinary ecretion of purine derivatives: on overview of the technical details. Occasional publication. Bucksburn Aberdeen. Ed. Rowett Research Institute, 1992. 21p.
COUTINHO FILHO, J.L.V.; HENRIQUE, W.; PERES, R.M. et al. Efeito da zeólita na engorda de bovinos em confinamento. Arch. Latinoamer. Prod. Anim., v.10, p.93-96, 2002.

DETMANN, E.; VALADARES FILHO, S.C.; PAULINO, M.F. Predição do valor energético de dietas para bovinos a partir da composição química dos alimentos. In: Exigências nutricionais de zebuínos puros e cruzados. (BR - CORTE). 3.ed. Viçosa, UFV, DZO. 2010, 193p.

FATEHI, F.; DEHGHAN-BANADAKY, M.; REZAYAZDI, K. et al. Effects of zeolytes on ruminants feeding. In: IRAN INTERNATIONAL ZEOLITE CONFERENCE (IIZC'08), Department of Animal Sciences, Agriculture faculty, University of Tehran, Iran- April 29 - May 1, 2008.

GALINDO, J.; ELIAS, A.; PIEDRA, R. The effect of some zeolite components on the rumen microbial activity of silage diets. Cuban J. Agric. Sci., v.24, p.187-194, 1990.

HALL, M.B. Neutral detergent-soluble carbohydrates: nutritional relevance and analysis, a laboratory manual. Florida: University of Florida, 2000. (Extension Bulletin 339).

HOOVER, W.H.; STOKES, S.R. Balancing carbohydrates and proteins for optimum rumen microbial yield. J. Dairy Sci., v.74, p.3630-3644, 1991.

JOHNSON, L.M.; HARRISON J.H.; RILEY, R.E. Estimation of the flow of microbial nitrogen to the duodenum using urinary uric acid or allantoin. $J$. Dairy Sci., v.81, p.2408-2420, 1998.

MANUAL Merck de Veterinária: um manual de diagnóstico, tratamento, prevenção e controle de doenças para o veterinário. 1997. (7.ed.). Roca, São Paulo

MCCOLLUM, F.T.; GALYEAN, M.L. Effects of clinoptilolite on rumen fermentation digestion and feedlot performance in beef steers fed high concentrate diets. J. Anim. Sci., v.56, p.517-524, 1983.

MUMPTON, F.A.; FISHMAN, P.H. The application of natural zeolites in animal science and aquaculture. J. Anim. Sci., v.45, p.1188-1203, 1977.

MYERS, W.D.; LUDDEN, P.A.; NAYIGIHUGU, V. et al. Technical Note: a procedure for the preparation and quantitative analysis of samples for titanium dioxide. J. Anim. Sci., v.82, p.179-183, 2004.

NUTRIENTS requirements of beef cattle. 7.ed. Washington, D.C., 2000. 244p

PARRÉ, C.; VIEIRA, P.F.; SILVEIRA, A.C. et al. Utilização de ureia e zeólita na alimentação de ovinos. Digestibilidade e balanço de nitrogênio. In: REUNIÃO DA SOCIEDADE BRASILEIRA DE 
ZOOTECNIA, 34., 1997, Juiz de Fora, MG. Anais... Juiz de Fora: Sociedade Brasileira de Zootecnia, 1997. 3 p.1 CD-ROM.

RENNÓ, N.L.; VALADARES, R.F.D.; VALADARES FILHO, S.C. et al. Concentração plasmática de ureia e excreção de ureia e creatinina em novilhos. Rev. Bras. Zootec., v.29, p.1235-1243, 2000.

RUSSELL, J.B.; O'CONNOR, J.D.; FOX, D.G. et al. Net carbohydrate and protein system for evaluating cattle diets. I. Ruminal fermentation. J. Anim. Sci. v.70, p.3551-3561, 1992.

RUSSELL, J.B.; CHOW, J.M. Another theory for the action of ruminal buffer salts: decreased starch fermentation and propionate production. J. Anim. Sci., v.76, p.826-830, 1993

SADEGHI, A.A.; SHAWRANG, P. The effect of natural zeolite on nutrient digestibility, carcass traits and performance of Holstein steers given a diet containing urea. J. Anim. Sci., v.82, p.163-167, 2006.

SILVA, D.J.; QUEIROZ, A.C. Análises de alimentos (métodos químicos e biológicos). 3.ed. Viçosa, MG: Editora UFV, 2002. 235p.

SILVA, R.M.N.; VALADARES, R.F.D; VALADARES FILHO, S.C. et al. Ureia para vacas em lactação. 2. Estimativa do volume urinário, da produção microbiana e da excreção de ureia. Rev. Bras. Zootec., v.30, p.1948-1957, 2001

STATISTICAL Analysis System - SAS/STAT User's Guide (Release 9.0), SAS Inst., Inc., Cary, NC. 2002.

SWEENEY, T.F.; POND, W.G.; MUMPTON, F.A. Effect of dietary clinoptilolite on digestion and rúmen fermentation in steers. Zeo-Agriculture: Use of Natural Zeolite in Agriculture and Aquaculture, p.177-187, 1983.

USHIDA, K.; LASSALAS, B.; JOUANY, J.P. Determination of assay parameters for RNA analysis in bacterial and duodenal samples by spectrophotometry. Influence of sample treatment and preservation. Reprod. Nutr. Develop., v.25, p.10371046, 1985.

VAN SOEST, P.J.; ROBERTSON, J.B. Analysis of forages and fibrous foods. Ithaca: Cornell University, 1985. 202p.

VERBIC, J.; CHEN, X.B.; MACLEOD, N.A. et al. Excretion of purine derivatives by ruminants. Effect of microbial nucleic acid infusion on purine derivative excretion by steers. J. Agric. Sci., v.114, p.243-248, 1990. 